\title{
Assessment of cerebrospinal fluid $\alpha$-synuclein as a potential biomarker in Parkinson's disease and synucleinopathies
}

\author{
Ioanna Chalatsa ${ }^{1}$, Katerina Melachroinou ${ }^{1}$, Evangelia Emmanouilidou ${ }^{1,2}$, Kostas Vekrellis ${ }^{1}$ \\ ${ }^{1}$ Center for Basic Science, Biomedical Research Foundation Academy of Athens, Athens 11527, Greece. \\ ${ }^{2}$ Laboratory of Biochemistry, Department of Chemistry, National and Kapodistrian University of Athens, Athens 11527, Greece.
}

Correspondence to: Dr. Kostas Vekrellis, Center for Basic Science, Biomedical Research Foundation Academy of Athens, 4 Soranou Ephessiou St., Athens 11527, Greece. E-mail: vekrellis@bioacademy.gr

How to cite this article: Chalatsa I, Melachroinou K, Emmanouilidou E, Vekrellis K. Assessment of cerebrospinal fluid $\alpha$-synuclein as a potential biomarker in Parkinson's disease and synucleinopathies. Neuroimmunol Neuroinflammation 2020;7:132-40. http://dx.doi.org/10.20517/2347-8659.2020.01

Received: 2 Jan 2020 First Decision: 10 Mar 2020 Revised: 23 Mar 2020 Accepted: 7 Apr 2020 Available online: 16 May 2020

Science Editor: George P. Paraskevas Copy Editor: Jing-Wen Zhang Production Editor: Jing Yu

\begin{abstract}
The discovery of diagnostic and prognostic biomarkers for neurodegenerative diseases represents an unmet clinical challenge. For example, the diagnosis of Parkinson's disease (PD) relies mainly on the presence of clinical symptoms. Therefore, the identification and use of novel PD biomarkers would allow the application of diseasemodifying treatments at the very early stages of neurodegeneration. The presynaptic protein, $\alpha$-synuclein, has been genetically and biochemically linked with PD pathogenesis and has been considered as a potential biomarker for the diagnosis of PD and the related synucleinopathies. The vast majority of studies have assessed the measurement of $\alpha$-synuclein, alone or in combination with other biomarkers in the cerebrospinal fluid (CSF), since it is the biofluid that most closely reflects the pathophysiology of the brain. The diagnostic value of the monomeric $\alpha$-synuclein but also the oligomeric, the phosphorylated and the aggregated forms of the protein has been evaluated using a variety of immunoassays. The results have so far been reproducible but the assays used are still lacking the required diagnostic accuracy. Recent reports have shown that Protein misfolding cyclic amplification is a technique that has the potential to detect $\alpha$-synuclein seeds in samples of CSF with high sensitivity and across different synucleinopathies. In an effort to increase the source of biomarker for PD and related synucleinopathies, $\alpha$-synuclein has also been measured in neuronal exosomes, small vesicles of endosomal origin that are secreted from neurons into the CSF or the periphery. The potential diagnostic value of exosomes stems from the notion that exosomes carry a disease-specific repertoire of marker proteins. Therefore, the assessment of exosomeassociated $\alpha$-synuclein species may also open up new avenues for disease diagnosis in different synucleinopathies.
\end{abstract}

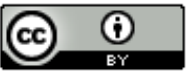

(C) The Author(s) 2020. Open Access This article is licensed under a Creative Commons Attribution 4.0 International License (https://creativecommons.org/licenses/by/4.0/), which permits unrestricted use, sharing, adaptation, distribution and reproduction in any medium or format, for any purpose, even commercially, as long as you give appropriate credit to the original author(s) and the source, provide a link to the Creative Commons license, and indicate if changes were made.

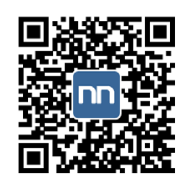


Keywords: Cerebrospinal fluid, $\alpha$-synuclein, Parkinson's disease, biomarker, exosomes, synucleinopathies

\section{INTRODUCTION}

The formation of large inclusions mostly containing protein aggregates is a common pathological hallmark in a wide spectrum of neurodegenerative disorders such as Alzheimer's Disease (AD) and Huntington Disease $^{[1]}$. Particularly three distinct neurological conditions, Parkinson's Disease (PD) including Parkinson's disease dementia, Dementia with Lewy Bodies (DLB) and Multiple System Atrophy (MSA), are characterized by the aberrant accumulation of the presynaptic protein $\alpha$-synuclein. In PD and DLB, $\alpha$-synuclein deposits are found either in the cytoplasm of neurons, where they are called lewy bodies (LB), or in the neuronal terminals, where they are called Lewy neurites ${ }^{[2]}$ whereas in MSA, $\alpha$-synuclein deposition occurs in glial cells. $\alpha$-Synuclein is also genetically linked with the development of PD since specific point mutations or multiplications (duplications, triplications) of the SNCA gene encoding for $\alpha$-synuclein result in the familial forms of $\mathrm{PD}^{[3-8]}$. The genetic association of $\alpha$-synuclein with $\mathrm{PD}$ is further strengthened by all the genome-wide association studies performed so far which indicate a strong correlation of PD with variations in the SNCA gene ${ }^{[9,10]}$. These biochemical and genetic linkages of $\alpha$-synuclein with pathology as well as the observation that the protein is present in biological fluids or peripheral tissues led to the assumption that $\alpha$-synuclein could serve as a potential candidate biomarker for $\mathrm{PD}$ diagnosis and also aid the differential diagnosis between the synucleinopathies ${ }^{[11]}$.

A plethora of studies have assessed the absolute quantification of $\alpha$-synuclein levels as a marker of synucleinopathy with the ultimate aim to discriminate PD patients from healthy subjects or other unrelated neurological controls. In this regard, understanding the structural biology of $\alpha$-synuclein is critical; the protein is highly modified at the post-translational level and has the ability to adopt different conformations depending on the surrounding milieu. From all the modifications that have been reported so far, phosphorylation is considered most closely related to PD pathology since almost $90 \%$ of $\alpha$-synuclein in LB appears to be hyper-phosphorylated ${ }^{[12]}$. In addition, the assembly into multiple-sized oligomers has been considered an early event in the pathological process of aggregate formation ${ }^{[13]}$. As such, different forms of $\alpha$-synuclein, i.e., monomeric, oligomeric and phosphorylated, have been targeted in order to increase diagnostic accuracy ${ }^{[14]}$. The measurements have been performed in bodily fluids [cerebrospinal fluid (CSF), blood plasma or serum, saliva], isolated secreted vesicles (exosomes) and peripheral tissues (skin, olfactory or gut mucosa, salivary gland) using a variety of analytical approaches depending on the nature of the biological sample and the form of $\alpha$-synuclein detected with each assay ${ }^{[15]}$.

In comparison with the other biological fluids, the assessment of $\alpha$-synuclein in the CSF has provided the most consistent results in terms of analytical validation by different laboratories ${ }^{[16]}$. CSF $\alpha$-synuclein is mostly detected by means of immunoassays that use specific antibodies to target the different $\alpha$-synuclein forms. Even though the absolute concentrations can vary from study to study, the results obtained so far are supported by several meta-analysis studies suggesting that CSF $\alpha$-synuclein could serve as a potential marker of synucleinopathy ${ }^{[17]}$. In this review, we aim to discuss the results from the assessment of $\alpha$-synuclein in CSF and exosomes and explain the factors responsible for the variability among the different studies.

\section{MEASUREMENT OF CSF $\alpha$-SYNUCLEIN}

Being primarily produced by the choroid plexus within the ventricles of the central nervous system, CSF is an established biological fluid to study neurodegenerative disorders since it is expected to mirror brain microenvironment. The quantification of total $\alpha$-synuclein, as well as its oligomeric and phosphorylated forms, can be measured in CSF using different techniques, such as ELISA ${ }^{[18]}$, xMAP technology ${ }^{[19]}$, 
mass spectrometry ${ }^{[20]}$, time-resolved fluorescence energy transfer ${ }^{[21]}$, electrochemiluminescence immunoassay ${ }^{[22]}$ and western blot ${ }^{[23]}$. In addition, new biochemical assays that can detect $\alpha$-synuclein aggregates have emerged, such as Protein-misfolding cyclic amplification and Real-time Quaking-induced conversion, by taking advantage the ability of $\alpha$-synuclein to nucleate further aggregation ${ }^{[24-26]}$. Using all these different methods, it is important to note that, even though there are variations in the absolute concentrations measured, the results produced for total (or monomeric) CSF $\alpha$-synuclein agree on a reduction in $\alpha$-synuclein levels in PD patients when compared with control subjects. When oligomeric or phosphorylated $\alpha$-synuclein was assessed in the CSF, both forms were found to be increased in PD patients compared with the controls. However, it is important to note that the of ligands such as ThT may affect the actual structure of the $\alpha$-synuclein species.

Even though the above findings are consistent, the diagnostic accuracy (sensitivity and specificity) remains unsatisfactory either for the detection of the monomeric or the modified forms of $\alpha$-synuclein. Additionally, some studies report contradictory results; some have found similar CSF $\alpha$-synuclein levels between PD patients and control subjects ${ }^{[27-29]}$, whereas others have reported increased CSF $\alpha$-synuclein levels in samples from $\mathrm{AD}^{[30,31]}$, progressive supranuclear palsy or Creutzfeldt-Jacob patients compared with the control group ${ }^{[32]}$.

A number of factors could explain the observed variability in the results, as well as the differences reported in the absolute concentrations. First, the immunoassays used are based on divergent antibodies that recognize different fragments of the protein and with variable affinity. Second, the patient cohorts show great variability in terms of number, disease stage and clinical symptoms (affected mobility or dementia) present at the time of CSF collection. Third, the implementation of strict standardized guidelines concerning collection and storage protocols and allowed blood contamination have only recently started to be followed. Furthermore, common reference materials are still missing making the interpretation of results from assay to assay extremely difficult.

The quantification of CSF $\alpha$-synuclein could aid the differential diagnosis in clinically overlapping neurodegenerative diseases, as suggested for $\mathrm{PD}, \mathrm{DLB}$ and $\mathrm{AD}^{[33-35]}$. However, it is unclear whether the levels of CSF $\alpha$-synuclein could be correlated with the severity of disease, indicating for example a more rapid decline in motor performance or the appearance of dementia. Interestingly, recent reports have shown that simultaneous measurement of $\alpha$-synuclein levels along with other proteins, such as tau, $A \beta_{42}$ and Glucocerebrosidase 1 could be more effective in discriminating PD patients with synucleinopathies from healthy individuals or those with other neurodegenerative diseases ${ }^{[30,36-38]}$.

Other biological fluids could also serve as promising candidates for $\alpha$-synuclein detection and subsequent PD diagnosis. The majority of reports studying plasma $\alpha$-synuclein have exhibited increased levels in PD patients ${ }^{[39-46]}$ relative to control subjects, whereas other studies have reported similar ${ }^{[27,47,48]}$ or decreased plasma $\alpha$-synuclein levels ${ }^{[49]}$ between PD patients and healthy participants. Interestingly, it was found that plasma levels of phosphorylated $\alpha$-synuclein were higher in the PD samples than the controls ${ }^{[44,50,51]}$. The results obtained from plasma have been controversial, mainly due to the fact that red blood cells are a major source of $\alpha$-synuclein and the rest erythrocytes that remain in plasma ${ }^{[52]}$ can be subjected to hemolysis markedly affecting $\alpha$-synuclein values ${ }^{[47]}$.

As erythrocytes are the major source of peripheral $\alpha$-synuclein, a recent report has proposed erythrocytic $\alpha$-synuclein as a potential PD biomarker, as it was found that the total and aggregated $\alpha$-synuclein levels were significantly higher in the membrane fraction of PD patients compared to healthy controls ${ }^{[53]}$. Saliva $\alpha$-synuclein has also been considered as a prospective biomarker, as $\alpha$-synuclein pathology has been found in submandibular salivary glands ${ }^{[54,55]}$ and saliva $\alpha$-synuclein could be easily accessible and poorly affected 
by blood contamination ${ }^{[56-59]}$. Some studies have reported that total $\alpha$-synuclein levels were reduced in the saliva of PD patients compared with control subjects, whereas oligomeric $\alpha$-synuclein appeared to be elevated in the saliva of PD patients ${ }^{[6,57]}$.

\section{MEASUREMENT OF $\alpha$-SYNUCLEIN FROM NEURONAL EXOSOMES AS A POTENTIAL BIOMARKER}

$\alpha$-synuclein was considered to be localized mostly in the cytoplasm of neuronal cells, until several studies demonstrated its presence in human CSF, human plasma and in the conditioned medium of various cell lines ${ }^{[23,60]}$. Many studies have shown that $\alpha$-synuclein is physiologically secreted in the extracellular space, but the mechanism of $\alpha$-synuclein release is still unclear. Evidence from recent studies has also suggested that extracellular $\alpha$-synuclein can confer to the progression of $\mathrm{PD}^{[1-3]}$ and it has been proposed that $\alpha$-synuclein secretion, either in a monomeric or oligomeric state, induces $\alpha$-synuclein propagation via cellto-cell transfer ${ }^{[6]]}$. Thus, elucidating the mechanism by which $\alpha$-synuclein is secreted in the extracellular space is of great importance in understanding cellular pathways that may cause PD.

Release of $\alpha$-synuclein via extracellular vesicles termed exosomes has been demonstrated by our group and others $^{[62,63]}$. Exosomes are extracellular vesicles of $\sim 50$ to $200 \mathrm{~nm}$ diameter and can mediate proximal and distal cellular communication through the transfer of biological molecules between cells. They originate from the inward budding of multi-vesicular bodies (MVBs) and are released to the extracellular space upon fusion of MVBs with the plasma membrane in an exocytic manner. Exosomes are released from numerous cell types including neurons and glia ${ }^{[64]}$ and in several studies have been observed to be associated with pathologic proteins including $\alpha$-synuclein ${ }^{[63,65]}$. Based on the current knowledge, exosomes are functionally active entities, with a highly versatile role, ranging from intercellular communication by delivering specific protein, lipid or RNA cargo, and removal of obsolete or misfolded proteins, as a means of cell detoxification, to deleterious shuttles that impair cell homeostasis ${ }^{[66]}$.

Some well-characterized functions of exosomes are protein secretion and intracellular uptake, immune response regulation and toxicity induction ${ }^{[67]}$. Interestingly, Danzer et al. ${ }^{[65]}$ demonstrated that exosome associated $\alpha$-synuclein is more potent in transmitting aggregation pathology between neurons than free-secreted $\alpha$-synuclein. One study has shown that patients with PD have higher $\alpha$-synuclein levels in plasma exosomes compared to healthy controls ${ }^{[68]}$, while Stuendl et al ${ }^{[69]}$ found decreased neural exosome $\alpha$-synuclein levels in PD patients, consistent with the total $\alpha$-synuclein levels in CSF. In addition, the quantification of CSF exosomal $\alpha$-synuclein exhibited distinct differences between patients with PD and DLB. Moreover, exosomal $\alpha$-synuclein levels correlated with the severity of cognitive impairment in cross-sectional samples from patients with DLB. In the same study, Stuendl et al ${ }^{[69]}$ showed that exosomes from PD and DLB patients contain pathogenic $\alpha$-synuclein species which serve as seeds to induce the oligomerization of soluble $\alpha$-synuclein in recipient cells. Shi et al. ${ }^{[70]}$ have shown that CNSderived exosomes can efflux into blood. Importantly, they found a substantially augmented $\alpha$-synuclein concentration in the plasma-isolated exosomes from PD patients compared to healthy control subjects, despite the fact that no differences were detected in plasma total $\alpha$-synuclein levels. Additionally, they report a significant increase of plasma exosomal $\alpha$-synuclein/total $\alpha$-synuclein ratio in PD patients, negatively correlated with the disease severity, further supporting the importance of the disease-related exosomal cargos as PD biomarkers with high sensitivity and specificity. The authors concluded that plasma, CNS-derived exosomal $\alpha$-synuclein can serve as a PD biomarker with high sensitivity and specificity ${ }^{[70]}$. The same group has also shown that CNS-derived exosomal tau in plasma is significantly higher in PD patients than in controls and is correlated with CSF total tau and phosphorylated tau ${ }^{[7]}$. Furthermore, distinct circulating exosome entities have been identified in the serum of patients with $\mathrm{PD}^{[72]}$. A recent study demonstrated that the levels of DJ-1 and $\alpha$-synuclein in plasma CSF-derived exosomes and the 
ratio of plasma CSF-derived exosomal DJ-1 to total DJ-1 were significantly higher in patients with PD, compared with controls ${ }^{[4]}$. Several factors have been shown to affect the release of $\alpha$-synuclein through exosomes such as the activity of Glucocerebrosidase enzyme (GCase), ion homeostasis, such as $\mathrm{Zn}^{2+}, \mathrm{Ca}^{2+}$ and $\mathrm{Mn}^{2+}$, as well as neuronal activity and neurotransmitter release. The heterozygous mutations in the GBA1 gene are considered as an important risk factor for PD. In this regard, it has been demonstrated that GCase overexpression leads to a decrease of exosome secretion while chronic pharmacological inhibition of GCase activity in vivo profoundly increased exosomes levels, as well as exosome-associated $\alpha$-synuclein oligomers ${ }^{[73]}$. In addition, decreased GCase activity has been demonstrated in brain samples with increased $\alpha$-synuclein levels and in CSF from sporadic PD patients ${ }^{[74]}$. More recently, a study by Cerri et al. ${ }^{[75]}$, showed that exosomes from PD patients contain a greater amount of $\alpha$-synuclein compared to healthy subjects whereas no differences were found in plasma total $\alpha$-synuclein levels. Importantly, the authors showed a significant inverse correlation between GCase activity and this ratio in PD patients.

Notably, exosomes being a snapshot of the intracellular milieu, comprise a great source of bioactive molecules, including various RNA species. In a study conducted by Gui and co-workers, where exosomal miRNAs were isolated from the CSF of PD patients, 16 and 11 exosomal miRNAs were found upregulated and down- regulated, respectively, in PD patients compared to controls ${ }^{[7]}$. Validated hits were found to be miR-1 and miR-19b-3p, significantly reduced in PD CSF exosomes, in contrast to miR-153, miR-409-3p, miR-10a-5p, and let-7g-3p which were found to be increased ${ }^{[76]}$. This evidence highlights the potential diagnostic value of CSF exosomal RNA in the assessment of PD.

Although the role of exosome-associated $\alpha$-synuclein as a potential biomarker remains relatively controversial, there are specific parameters that should be taken into account. Firstly, with regards to the source of exosomes, including plasma, saliva, CSF, there are certain protocols for their acquisition, followed by even more meticulous procedures for exosome isolation and purification. Differences during the aforementioned protocols may account for deviations between groups. In the same context, total exosome isolation may mask differences that could be found in exosomes of specific cellular origin. For example, Tomlinson and colleagues ${ }^{[72]}$, following an unbiased proteomic approach, did not find any significant increase of $\alpha$-synuclein in total exosomes isolated by ultracentrifugation from the serum of PD patients. On the contrary, Shi et al. ${ }^{[70]}$ showed a significant $\alpha$-synuclein enrichment in neuron-specific exosomes, isolated from PD patients' plasma by immunoprecipitation of the neuronal adhesion molecule L1CAM. More importantly, the notion that $\alpha$-synuclein exists and exerts its detrimental effects in different strains, leading to different aggregates that cause as many distinct synucleinopathies, i.e., PD, DLB, MSA has been cemented $^{[77,78]}$. Given the fact that exosomal cargo mirrors the state of the cell from which it originates, exosome-associated $\alpha$-synuclein may reflect the dynamic nature of $\alpha$-synuclein species. To this end, it is of a pivotal importance to develop techniques that could allow detection and quantification of all the different $\alpha$-synuclein conformers. Overall, although in its infancy, the study of exosome-associated $\alpha$-synuclein as a potential biomarker is quite promising, yet, it requires more combinatorial approaches.

\section{CONCLUSION}

Over the last 10 years there has been considerable amount of research effort placed in the evaluation of neuronal $\alpha$-synuclein as a diagnostic or, even, a prognostic biomarker for PD and related synucleinopathies. The majority of studies have indicated that CSF $\alpha$-synuclein could be useful for the diagnosis of synucleinopathy that could also aid the distinguishment of PD patients from patients with other neurodegenerative conditions. However, its utility as a biomarker is hampered by the lack of a universally validated assay of high diagnostic accuracy. To this end, following the strict recently established standard operating protocols for CSF collection and storage and correlating the measurement of monomeric $\alpha$-synuclein with the oligomeric or phosphorylated forms would greatly improve the diagnostic value of the assessment of $\alpha$-synuclein in CSF. To further ameliorate the specificity of $\alpha$-synuclein measurement, recent 
experimental approaches involve the assessment of $\alpha$-synuclein in neural exosomes. The discoveries of pathogenic misfolded proteins such as $\alpha$-synuclein in them has generated intensive research into their use as biomarkers considering that they carry proteins with disease-specific fingerprints reflecting the presence and staging of the disease. However, in order to further verify this potential we need to have a very good understanding of the actual mechanisms behind their biogenesis and release. Importantly, we need to have those tools in place that will assist us in the identification of the $\alpha$-synuclein species responsible for disease generation and pathology progression. The fact that exosomal cargo mirrors the state of the cell from which it originates ${ }^{[79]}$ unravels the promising role of the plasma/CSF -derived exosomes as potential biomarkers. Proteomic profiling of exosomal proteins in PD patients with different disease stages and healthy subjects may also aid the identification of specific protein changes that occur in response to pathology progression. Finally, modulating exosome biogenesis and release may have a promising prospect in PD therapy.

\section{DECLARATIONS}

\section{Authors' contributions}

Contributed to the writing of the manuscript and in its revision: Chalatsa I, Melachroinou K, Emmanouilidou E, Vekrellis K

\section{Availability of data and materials}

Not applicable.

\section{Financial support and sponsorship}

None.

\section{Conflicts of interest}

All authors declared that there are no conflicts of interest.

\section{Ethical approval and consent to participate}

Not applicable.

\section{Consent for publication}

Not applicable.

\section{Copyright}

(c) The Author(s) 2020.

\section{REFERENCES}

1. Uversky VN. Neuropathology, biochemistry, and biophysics of alpha-synuclein aggregation. J Neurochem 2007;103:17-37.

2. Spillantini MG, Schmidt ML, Lee VM, Trojanowski JQ, Jakes R, et al. Alpha-synuclein in Lewy bodies. Nature 1997;388:839-40.

3. Polymeropoulos MH, Lavedan C, Leroy E, Ide SE, Dehejia A, et al. Mutation in the alpha-synuclein gene identified in families with Parkinson's disease. Science 1997;276:2045-7.

4. Zarranz JJ, Alegre J, Gómez-Esteban JC, Lezcano E, Ros R, et al. The new mutation, E46K, of alpha-synuclein causes Parkinson and Lewy body dementia. Ann Neurol 2004;55:164-73.

5. Proukakis C, Houlden H, Schapira AH. Somatic alpha-synuclein mutations in Parkinson's disease: hypothesis and preliminary data. Mov Disord 2013;28:705-12.

6. Lesage S, Le Ber I, Condroyer C, Broussolle E, Gabelle A, et al. C9orf72 repeat expansions are a rare genetic cause of parkinsonism. Brain 2013;136:385-91.

7. Chartier-Harlin MC, Kachergus J, Roumier C, Mouroux V, Douay X, et al. Alpha-synuclein locus duplication as a cause of familial Parkinson's disease. Lancet 2004;364:1167-9.

8. Singleton AB, Farrer MJ, Bonifati V. The genetics of Parkinson's disease: progress and therapeutic implications. Mov Disord 2013;28:14-23.

9. Satake W, Nakabayashi Y, Mizuta I, Hirota Y, Ito C, et al. Genome-wide association study identifies common variants at four loci as genetic risk factors for Parkinson's disease. Nat Genet 2009;41:1303-7. 
10. Simón-Sánchez J, Schulte C, Bras JM, Sharma M, Gibbs JR, et al. Genome-wide association study reveals genetic risk underlying Parkinson's disease. Nat Genet 2009;41:1308-12.

11. Emamzadeh FN, Surguchov A. Parkinson's disease: biomarkers, treatment, and risk factors. Front Neurosci 2018;12:612.

12. Fujiwara H, Hasegawa M, Dohmae N, Kawashima A, Masliah E, et al. alpha-Synuclein is phosphorylated in synucleinopathy lesions. Nat Cell Biol 2002;4:160-4.

13. Paleologou KE, Kragh CL, Mann DM, Salem SA, Al-Shami R, et al. Detection of elevated levels of soluble alpha-synuclein oligomers in post-mortem brain extracts from patients with dementia with Lewy bodies. Brain 2009;132:1093-101.

14. Surguchov A. Parkinson's disease: assay of phosphorylated alpha-synuclein in skin biopsy for early diagnosis and association with melanoma. Brain Sci 2016;6.

15. Mollenhauer B, Bowman FD, Drake D, Duong J, Blennow K, et al. Antibody-based methods for the measurement of $\alpha$-synuclein concentration in human cerebrospinal fluid - method comparison and round robin study. J Neurochem 2019;149:126-38.

16. Magdalinou N, Lees AJ, Zetterberg H. Cerebrospinal fluid biomarkers in parkinsonian conditions: an update and future directions. J Neurol Neurosurg Psychiatry 2014;85:1065-75.

17. Eusebi P, Hansson O, Paciotti S, Orso M, Chiasserini D, et al. Cerebrospinal fluid biomarkers for the diagnosis and prognosis of Parkinson's disease: protocol for a systematic review and individual participant data meta-analysis. BMJ Open 2017;7:e018177.

18. Mollenhauer B, Caspell-Garcia CJ, Coffey CS, Taylor P, Singleton A, et al. Longitudinal analyses of cerebrospinal fluid $\alpha$-Synuclein in prodromal and early Parkinson's disease. Mov Disord 2019;34:1354-64.

19. Hong Z, Shi M, Chung KA, Quinn JF, Peskind ER, et al. DJ-1 and alpha-synuclein in human cerebrospinal fluid as biomarkers of Parkinson's disease. Brain 2010;133:713-26.

20. Mollenhauer B, Cullen V, Kahn I, Krastins B, Outeiro TF, et al. Direct quantification of CSF alpha-synuclein by ELISA and first crosssectional study in patients with neurodegeneration. Exp Neurol 2008;213:315-25.

21. van Dijk KD, Bidinosti M, Weiss A, Raijmakers P, Berendse HW, et al. Reduced $\alpha$-synuclein levels in cerebrospinal fluid in Parkinson's disease are unrelated to clinical and imaging measures of disease severity. Eur J Neurol 2014;21:388-94.

22. Kruse N, Mollenhauer B. Quantification of alpha-synuclein in biological fluids by electrochemiluminescence-based detection. Methods Mol Biol 2019;1948:59-68.

23. Borghi R, Marchese R, Negro A, Marinelli L, Forloni G, et al. Full length alpha-synuclein is present in cerebrospinal fluid from Parkinson's disease and normal subjects. Neurosci Lett 2000;287:65-7.

24. Saijo E, Groveman BR, Kraus A, Metrick M, Orrù CD, et al. Ultrasensitive RT-QuIC seed amplification assays for disease-associated tau, $\alpha$-synuclein, and prion aggregates. Methods Mol Biol 2019;1873:19-37.

25. Shahnawaz M, Mukherjee A, Pritzkow S, Mendez N, Rabadia P, et al. Discriminating alpha-synuclein strains in Parkinson's disease and multiple system atrophy. Nature 2020;578:273-7.

26. Shahnawaz M, Tokuda T, Waragai M, Mendez N, Ishii R, et al. Development of a biochemical diagnosis of Parkinson disease by detection of $\alpha$-synuclein misfolded aggregates in cerebrospinal fluid. JAMA Neurol 2017;74:163-72.

27. Park MJ, Cheon SM, Bae HR, Kim SH, Kim JW. Elevated levels of $\alpha$-synuclein oligomer in the cerebrospinal fluid of drug-naïve patients with Parkinson's disease. J Clin Neurol 2011;7:215-22.

28. Ohrfelt A, Grognet P, Andreasen N, Wallin A, Vanmechelen E, et al. Cerebrospinal fluid alpha-synuclein in neurodegenerative disorders-a marker of synapse loss. Neurosci Lett 2009;450:332-5.

29. Aerts MB, Esselink RA, Abdo WF, Bloem BR, Verbeek MM. CSF $\alpha$-synuclein does not differentiate between parkinsonian disorders. Neurobiol Aging 2012;33:430.e1-3.

30. García-Ayllón MS, Monge-Argilés JA, Monge-García V, Navarrete F, Cortés-Gómez MA, et al. Measurement of CSF $\alpha$-synuclein improves early differential diagnosis of mild cognitive impairment due to Alzheimer's disease. J Neurochem 2019;150:218-30.

31. Twohig D, Rodriguez-Vieitez E, Sando SB, Berge G, Lauridsen C, et al. The relevance of cerebrospinal fluid $\alpha$-synuclein levels to sporadic and familial Alzheimer's disease. Acta Neuropathol Commun 2018;6:130.

32. Oeckl P, Metzger F, Nagl M, von Arnim CA, Halbgebauer S, et al. Alpha-, beta-, and gamma-synuclein quantification in cerebrospinal fluid by multiple reaction monitoring reveals increased concentrations in Alzheimer's and Creutzfeldt-Jakob disease but no alteration in synucleinopathies. Mol Cell Proteomics 2016;15:3126-38.

33. Katayama T, Sawada J, Kikuchi-Takeguchi S, Kano K, Takahashi K, et al. Cerebrospinal fluid levels of alpha-synuclein, amyloid $\beta$, tau, phosphorylated tau, and neuron-specific enolase in patients with Parkinson's disease, dementia with Lewy bodies or other neurological disorders: their relationships with cognition and nuclear medicine imaging findings. Neurosci Lett 2019;715:134564.

34. Bougea A, Stefanis L, Paraskevas GP, Emmanouilidou E, Efthymiopoulou E, et al. Neuropsychiatric symptoms and $\alpha$-Synuclein profile of patients with Parkinson's disease dementia, dementia with Lewy bodies and Alzheimer's disease. J Neurol 2018;265:2295-301.

35. Bongianni M, Ladogana A, Capaldi S, Klotz S, Baiardi S, et al. $\alpha$-Synuclein RT-QuIC assay in cerebrospinal fluid of patients with dementia with Lewy bodies. Ann Clin Transl Neurol 2019;6:2120-6.

36. Lerche S, Wurster I, Roeben B, Zimmermann M, Riebenbauer B, et al. Parkinson's disease: glucocerebrosidase 1 mutation severity is associated with CSF alpha-synuclein profiles. Mov Disord 2020;35:495-9.

37. Viodé A, Epelbaum S, Benyounes I, Verny M, Dubois B, et al. Simultaneous quantification of tau and $\alpha$-synuclein in cerebrospinal fluid by high-resolution mass spectrometry for differentiation of Lewy Body Dementia from Alzheimer's disease and controls. Analyst 2019;144:6342-51.

38. Shi M, Tang L, Toledo JB, Ginghina C, Wang H, et al. Cerebrospinal fluid $\alpha$-synuclein contributes to the differential diagnosis of Alzheimer's disease. Alzheimers Dement 2018;14:1052-62. 
39. Chen XQ, Niu JP, Peng RQ, Song YH, Xu N, et al. The early diagnosis of Parkinson's disease through combined biomarkers. Acta Neurol Scand 2019;140:268-73.

40. Duran R, Barrero FJ, Morales B, Luna JD, Ramirez M, et al. Plasma alpha-synuclein in patients with Parkinson's disease with and without treatment. Mov Disord 2010;25:489-93.

41. Lee PH, Lee G, Park HJ, Bang OY, Joo IS, et al. The plasma alpha-synuclein levels in patients with Parkinson's disease and multiple system atrophy. J Neural Transm 2006;113:1435-9.

42. Chang CW, Yang SY, Yang CC, Chang CW, Wu YR. Plasma and serum alpha-synuclein as a biomarker of diagnosis in patients with Parkinson's disease. Front Neurol 2019;10:1388.

43. Ng ASL, Tan YJ, Lu Z, Ng EYL, Ng SYE, et al. Plasma alpha-synuclein detected by single molecule array is increased in PD. Ann Clin Transl Neurol 2019;6:615-9.

44. Lin CH, Liu HC, Yang SY, Yang KC, Wu CC, et al. Plasma pS129-alpha-synuclein is a surrogate biofluid marker of motor severity and progression in Parkinson's disease. J Clin Med 2019;8.

45. Lin CH, Yang SY, Horng HE, Yang CC, Chieh JJ, et al. Plasma biomarkers differentiate Parkinson's disease from atypical parkinsonism syndromes. Front Aging Neurosci 2018;10:123.

46. Lin CH, Yang SY, Horng HE, Yang CC, Chieh JJ, et al. Plasma alpha-synuclein predicts cognitive decline in Parkinson's disease. J Neurol Neurosurg Psychiatry 2017;88:818-24.

47. Shi M, Zabetian CP, Hancock AM, Ginghina C, Hong Z, et al. Significance and confounders of peripheral DJ-1 and alpha-synuclein in Parkinson's disease. Neurosci Lett 2010;480:78-82.

48. Mata IF, Shi M, Agarwal P, Chung KA, Edwards KL, et al. SNCA variant associated with Parkinson disease and plasma alpha-synuclein level. Arch Neurol 2010;67:1350-6.

49. Li QX, Mok SS, Laughton KM, McLean CA, Cappai R, et al. Plasma alpha-synuclein is decreased in subjects with Parkinson's disease. Exp Neurol 2007;204:583-8.

50. Cariulo C, Martufi P, Verani M, Azzollini L, Bruni G, et al. Phospho-S129 alpha-synuclein is present in human plasma but not in cerebrospinal fluid as determined by an ultrasensitive immunoassay. Front Neurosci 2019;13:889.

51. Foulds PG, Diggle P, Mitchell JD, Parker A, Hasegawa M, et al. A longitudinal study on alpha-synuclein in blood plasma as a biomarker for Parkinson's disease. Sci Rep 2013;3:2540.

52. Barbour R, Kling K, Anderson JP, Banducci K, Cole T, et al. Red blood cells are the major source of alpha-synuclein in blood. Neurodegener Dis 2008;5:55-9.

53. Tian C, Liu G, Gao L, Soltys D, Pan C, et al. Erythrocytic alpha-Synuclein as a potential biomarker for Parkinson's disease. Transl Neurodegener 2019;8:15.

54. Adler CH, Serrano GE, Zhang N, Hinni ML, Lott DG, et al. Feasibility of repeat and bilateral submandibular gland needle biopsies in Parkinson's disease. Parkinsonism Relat Disord 2019;68:69-72.

55. Del Tredici K, Hawkes CH, Ghebremedhin E, Braak H. Lewy pathology in the submandibular gland of individuals with incidental Lewy body disease and sporadic Parkinson's disease. Acta Neuropathol 2010;119:703-13

56. Kang W, Chen W, Yang Q, Zhang L, Zhang L, et al. Salivary total alpha-synuclein, oligomeric alpha-synuclein and SNCA variants in Parkinson's disease patients. Sci Rep 2016;6:28143.

57. Vivacqua G, Suppa A, Mancinelli R, Belvisi D, Fabbrini A, et al. Salivary alpha-synuclein in the diagnosis of Parkinson's disease and Progressive Supranuclear Palsy. Park Relat Disord 2019;63:143-8.

58. Al-Nimer MSM, Mshatat SF, Abdulla HI. Saliva alpha-synuclein and a high extinction coefficient protein: a novel approach in assessment biomarkers of Parkinson's disease. N Am J Med Sci 2014;6:633-7.

59. Devic I, Hwang H, Edgar JS, Izutsu K, Presland R, et al. Salivary alpha-synuclein and DJ-1: potential biomarkers for Parkinson's disease. Brain 2011;134:178.

60. Lee HJ, Patel S, Lee SJ. Intravesicular localization and exocytosis of alpha-synuclein and its aggregates. J Neurosci 2005;25:6016-24.

61. Recasens A, Dehay B. Alpha-synuclein spreading in Parkinson's disease. Front Neuroanat 2014;8:159.

62. Alvarez-Erviti L, Seow Y, Schapira AH, Gardiner C, Sargent IL, et al. Lysosomal dysfunction increases exosome-mediated alphasynuclein release and transmission. Neurobiol Dis 2011;42:360-7.

63. Emmanouilidou E, Melachroinou K, Roumeliotis T, Garbis SD, Ntzouni M, et al. Cell-produced alpha-synuclein is secreted in a calciumdependent manner by exosomes and impacts neuronal survival. J Neurosci 2010;30:6838-51.

64. Von Bartheld CS, Altick AL. Multivesicular bodies in neurons: distribution, protein content, and trafficking functions. Prog Neurobiol 2011;93:313-40.

65. Danzer KM, Kranich LR, Ruf WP, Cagsal-Getkin O, Winslow AR, et al. Exosomal cell-to-cell transmission of alpha synuclein oligomers Mol Neurodegener 2012;7:42.

66. Bellingham SA, Guo BB, Coleman BM, Hill AF. Exosomes: vehicles for the transfer of toxic proteins associated with neurodegenerative diseases. Front Physiol 2012;3:124.

67. Chang C, Lang H, Geng N, Wang J, Li N, et al. Exosomes of BV-2 cells induced by alpha-synuclein: important mediator of neurodegeneration in PD. Neurosci Lett 2013;548:190-5.

68. Zhao ZH, Chen ZT, Zhou RL, Zhang X, Ye QY, et al. Increased DJ-1 and $\alpha$-synuclein in plasma neural-derived exosomes as potential markers for Parkinson's disease. Front Aging Neurosci 2018;10:438.

69. Stuendl A, Kunadt M, Kruse N, Bartels C, Moebius W, et al. Induction of $\alpha$-synuclein aggregate formation by CSF exosomes from patients with Parkinson's disease and dementia with Lewy bodies. Brain 2016;139:481-94. 
70. Shi M, Liu C, Cook TJ, Bullock KM, Zhao Y, et al. Plasma exosomal $\alpha$-synuclein is likely CNS-derived and increased in Parkinson's disease. Acta Neuropathol 2014;128:639-50.

71. Shi M, Kovac A, Korff A, Cook TJ, Ginghina C, et al. CNS tau efflux via exosomes is likely increased in Parkinson's disease but not in Alzheimer's disease. Alzheimers Dement 2016;12:1125-31.

72. Tomlinson PR, Zheng Y, Fischer R, Heidasch R, Gardiner C, et al. Identification of distinct circulating exosomes in Parkinson's disease. Ann Clin Transl Neurol 2015;2:353-61.

73. Papadopoulos VE, Nikolopoulou G, Antoniadou I, Karachaliou A, Arianoglou G, et al. Modulation of $\beta$-glucocerebrosidase increases $\alpha$-synuclein secretion and exosome release in mouse models of Parkinson's disease. Hum Mol Genet 2018;27:1696-710.

74. Parnetti L, Paciotti S, Eusebi P, Dardis A, Zampieri S, et al. Cerebrospinal fluid $\beta$-glucocerebrosidase activity is reduced in parkinson's disease patients. Mov Disord 2017;32:1423-31.

75. Cerri S, Ghezzi C, Sampieri M, Siani F, Avenali M, et al. The exosomal/total $\alpha$-synuclein ratio in plasma is associated with glucocerebrosidase activity and correlates with measures of disease severity in PD patients. Front Cell Neurosci 2018;12:125.

76. Gui YX, Liu H, Zhang LS, Lv W, Hu XY. Altered microRNA profiles in cerebrospinal fluid exosome in Parkinson disease and Alzheimer disease. Oncotarget 2015;6:37043-53.

77. Peelaerts W, Bousset L, Van der Perren A, Moskalyuk A, Pulizzi R, et al. alpha-Synuclein strains cause distinct synucleinopathies after local and systemic administration. Nature 2015;522:340-4.

78. Lee SJ, Masliah E. Neurodegeneration: aggregates feel the strain. Nature 2015;522:296-7.

79. De Toro J, Herschlik L, Waldner C, Mongini C. Emerging roles of exosomes in normal and pathological conditions: new insights for diagnosis and therapeutic applications. Front Immunol.2015;6:203. 